\title{
RNA Binding Protein Regulation and Cross-Talk in the Control of AU-rich mRNA Fate
}

\author{
Sofía M. García-Mauriño, Francisco Rivero-Rodríguez, Alejandro Velázquez-Cruz, \\ Marian Hernández-Vellisca, Antonio Díaz-Quintana, Miguel A. De la Rosa and \\ Irene Díaz-Moreno* \\ Instituto de Investigaciones Químicas, Centro de Investigaciones Cientificas Isla de la Cartuja, Universidad de Sevilla, \\ Consejo Superior de Investigaciones Científicas, Seville, Spain
}

OPEN ACCESS

Edited by:

Maria Rosaria Conte,

King's College London,

United Kingdom

Reviewed by:

Graeme L. Conn,

Emory University School of Medicine,

United States

Santiago Martinez-Lumbreras,

King's College London,

United Kingdom

Scott A. Tenenbaum

University at Albany, Suny,

United States

Teresa Carlomagno,

Leibniz University of Hanover

Germany

*Correspondence:

Irene Díaz-Moreno

idiazmoreno@us.es

Specialty section:

This article was submitted to

Structural Biology,

a section of the journal

Frontiers in Molecular Biosciences

Received: 26 July 2017 Accepted: 04 October 2017 Published: 23 October 2017

Citation:

García-Mauriño $S M$ Rivero-Rodríguez F, Velázquez-Cruz A, Hernández-Vellisca M

Díaz-Quintana A, De la Rosa MA and Díaz-Moreno I (2017) RNA Binding Protein Regulation and Cross-Talk in the Control of AU-rich mRNA Fate.

Front. Mol. Biosci. 4:71.

doi: 10.3389/fmolb.2017.00071
mRNA metabolism is tightly orchestrated by highly-regulated RNA Binding Proteins (RBPs) that determine mRNA fate, thereby influencing multiple cellular functions across biological contexts. Here, we review the interplay between six well-known RBPs (TTP, AUF-1, KSRP, HuR, TIA-1, and TIAR) that recognize AU-rich elements (AREs) at the $3^{\prime}$ untranslated regions of mRNAs, namely ARE-RBPs. Examples of the links between their cross-regulations and modulation of their targets are analyzed during mRNA processing, turnover, localization, and translational control. Furthermore, ARE recognition can be self-regulated by several factors that lead to the prevalence of one RBP over another. Consequently, we examine the factors that modulate the dynamics of those protein-RNA transient interactions to better understand the final consequences of the regulation mediated by ARE-RBPs. For instance, factors controlling the RBP isoforms, their conformational state or their post-translational modifications (PTMs) can strongly determine the fate of the protein-RNA complexes. Moreover, mRNA specific sequence and secondary structure or subtle environmental changes are also key determinants to take into account. To sum up, the whole understanding of such a fine tuned regulation is a challenge for future research and requires the integration of all the available structural and functional data by in vivo, in vitro and in silico approaches.

Keywords: mRNA fate, post-transcriptional regulation, RNA binding proteins, stability, translation

\section{POST-TRANSCRIPTIONAL REGULATION OF GENE EXPRESSION BY ARE-RBPs}

In eukaryotes, gene expression levels and protein abundance are often correlated but are subjected to a strict regulation. The control of mRNA metabolism allows cells to rapidly adapt to changing environmental conditions. Regulatory processes occurring after mRNA transcription-namely post-transcriptional control-strongly influence mRNA fate and, consequently, final protein levels (Vogel and Marcotte, 2012). Once mRNA transcription occurs in the nucleus, RNA Binding Proteins (RBPs) recognize the primary transcript or pre-mRNA to regulate its alternative splicing, polyadenylation, and capping (Figure 1). The generated mature mRNA is then transported to the cytoplasm by various other RBPs. Once in the cytoplasm, RBPs govern the stability, distribution to different cellular compartments and the translation of target mRNAs into their corresponding protein products (Matoulkova et al., 2012). 


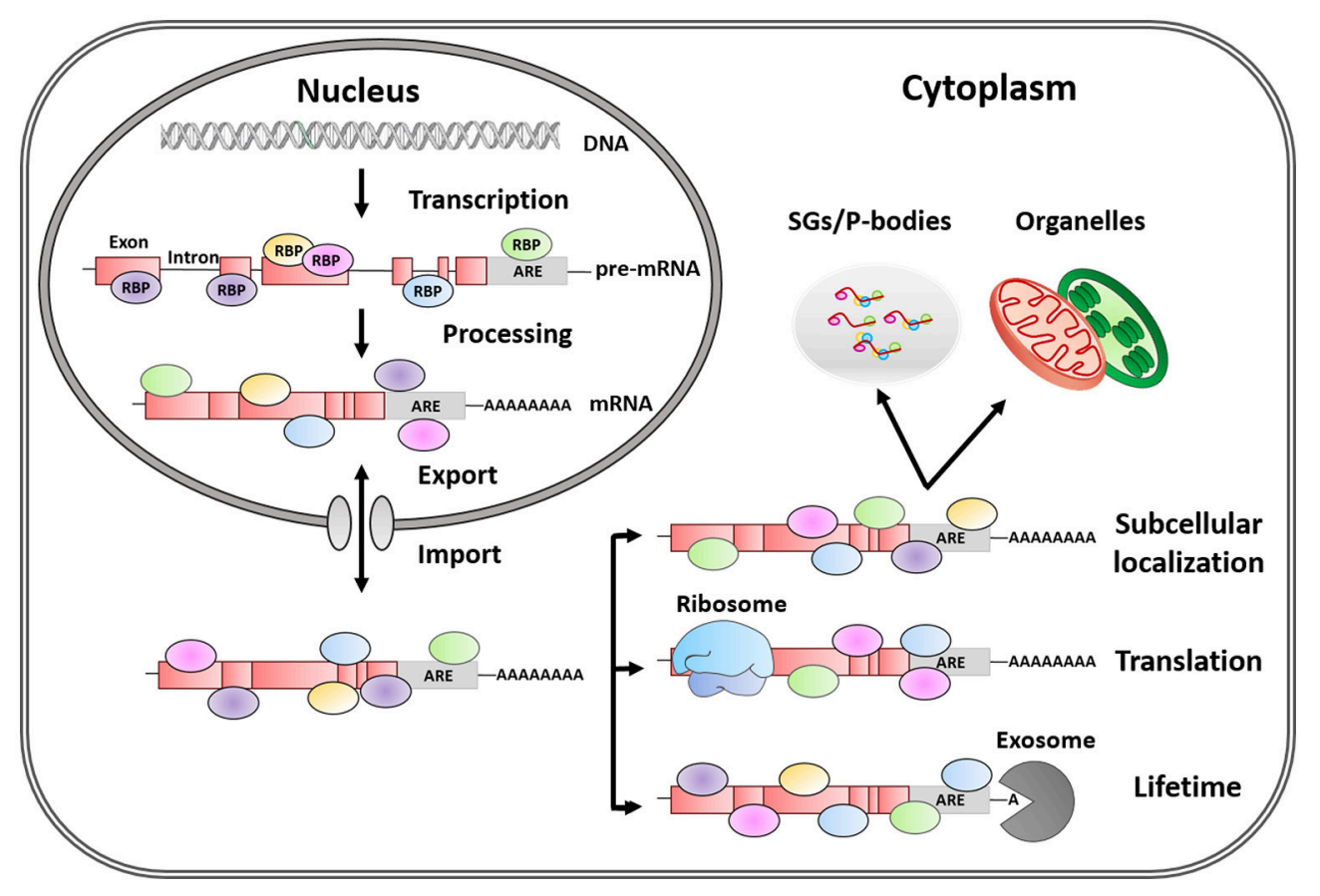

FIGURE 1 | Post-transcriptional regulation of mRNA fate by RNA-binding proteins. RBPs are trans-acting elements, that shuttle between the nucleus and the cytoplasm, and influence mRNA fate by binding to regulatory sequences (cis-acting elements). AREs are the most common regulatory elements in $3^{\prime}$ UTR, and the binding of RBPs to these regions plays a key role in the life of mRNAs by regulating alternative mRNA splicing, maturation, transport, subcellular location, lifetime, and translation.

Within RBPs, ARE-RBPs function as trans-acting factors recognizing cis-acting elements in the $3^{\prime}$-Unstranslated Regions (UTR) of eukaryotic mRNA enriched in adenylate and uridylate (AU-rich elements or AREs). AREs are present in 5-8\% of human genes with diverse functions such as cell growth and differentiation, signal transduction, apoptosis, nutrient transport, and metabolism. This list is dominated by genes involved in transient processes, which therefore require strict expression control (Barreau et al., 2005). For instance, the length and specific pattern of AREs may contribute to mRNA lifetime (Khabar, 2005). However, the final mRNA fate will be determined by the variable and dynamic ARE-RBPs/mRNA interactions or by RBP competition for the same transcript. Besides, ARE-RBPs bind to AREs via a variety of domains including the so-called RNA-Recognition Motif (RRM), the $\mathrm{CCCH}$ tandem zinc finger and the K-Homology domain (KH) (Stoecklin and Anderson,

\footnotetext{
Abbreviations: AREs, AU-Rich Elements; ARE-RBPs, RNA Binding Proteins that recognize AU-Rich Elements; AUF-1, AU-binding Factor 1; c-fos, FinkelBiskis-Jinkins murine osteosarcoma viral oncogene homolog; c-myc, Avian myelocytomatosis virus oncogene cellular homolog; COX-2, Cyclooxygenase-2; DDR, DNA Damage Response; hnRNPD, Heterogeneous Nuclear RiboNucleoProtein D; HuR, Human antigen R; KH, hnRNP K-Homology; KSRP, KH type Splicing Regulatory Protein; PAR, Poly (ADP-Ribose); P-bodies, Processing bodies; PTMs, Post-Translational Modifications; PRD, Prion-Related Domain; RBPs, RNA Binding Proteins; RNPs, Ribonucleoprotein Particles; RRM, RNA Recognition Motif; SGs, Stress Granules; TIA-1, T-cell Intracellular Antigen 1; TIAR, TIA1 Related protein; TNF $\alpha$, Tumor Necrosis Factor $\alpha$; TTP, Tristetraprolin; UTR, Untranslated Region; VEGF, Vascular Endothelial Growth Factor.
}

2006; Clery et al., 2008; Valverde et al., 2008; Daubner et al., 2013). A single protein can contain several of these motifs leading to simultaneous interactions with either multiple targets or multiple sites within a particular target (Shen and Malter, 2015). Additionally, most ARE-RBPs shuttle between nucleus and cytoplasm; and their functions are linked to their specific subcellular distribution (Gama-Carvalho and Carmo-Fonseca, 2001).

In this mini-review we focus on the post-transcriptional regulation exerted by six of the best studied ARE-RBPs whose cross-talk has biological relevance and has been widely reported in the literature. Moreover, we examine the multiple intracellular signals and factors controlling the interactions between these proteins. AU-binding Factor 1 (AUF1), also known as Heterogeneous Nuclear RiboNucleo-Protein D (hnRNPD), is included for being the first identified ARE-RBP (Brewer, 1991). AUF1 is generally considered to promote the decay of target mRNAs, although the stabilization of some other transcripts has been also reported (Xu et al., 2001; Stoecklin and Anderson, 2006). Since AUF1 discovery, 20 additional ARE-RBPs have been identified. That list includes those that primarily promote mRNA degradation, such as Tristetraprolin (TTP) and $\mathrm{KH}$ domainsplicing regulatory protein (KSRP) (Gherzi et al., 2004; Sanduja et al., 2011); those stabilizing mRNA, such as Human antigen R (HuR) (Brennan and Steitz, 2001); and translational control proteins, such as T-cell intracellular antigen 1 (TIA-1) and TIA1-related protein (TIAR) (Kawai et al., 2006; Mazan-Mamczarz et al., 2006). 


\section{INTERPLAY BETWEEN ARE-RBPS IN THE POST-TRANSCRIPTIONAL REGULATION OF mRNAs}

It is well-known that the substrates of post-transcriptional control are RNA ribonucleoprotein particles or RNPs containing mRNA molecules covered with RBPs, rather than naked mRNA (Szostak and Gebauer, 2013) (Figure 1). However, our understanding of how ARE-RBPs interact with each other at different regulatory levels is rather limited. Noticeably, some RBPs regulate the mRNA that encodes their own gene products, as well as those of other RBP counterparts, establishing selfregulatory loops controlling mRNA metabolism (Pullmann et al., 2007).

A good example of cross-talk between RBPs is the one involving HuR, KSRP and TTP proteins. These three proteins compete with each other for binding to common recognition sequences in the AREs that they regulate. Hence, TTP and KSRP negatively control the stability of several mRNAs-such as c-fos, $\mathrm{TNF} \alpha$ and COX-2-whereas HuR generally acts in an opposite way, stabilizing them (Chen et al., 2001, 2002; Dean et al., 2001; Sawaoka et al., 2003; Katsanou et al., 2005; Winzen et al., 2007) with some exceptions (Katsanou et al., 2005; Kim et al., 2009) (Table 1). Moreover, TTP acts as a negative regulator of its own mRNA (Tchen et al., 2004; Lin et al., 2007) as well as HuR mRNA, its direct antagonist in mRNA regulation (Al-Ahmadi et al., 2009). On the other hand, HuR acts as a positive translational regulator of both KSRP and HuR mRNAs (Pullmann et al., 2007; Yi et al., 2010); while both proteins regulate the stability of their own mRNAs (Winzen et al., 2007; Al-Ahmadi et al., 2009) (Table 1, dashed square). Consequently, the redundant feedback involving KSRP, TTP, and HuR may provide a bi-stable signal transduction circuit in which either all or none of their target mRNAs are stabilized and/or translated. More intriguingly is the role of AUF1 in this regulatory loop as it presents four isoforms generated by alternative splicing of a single mRNA transcript (Wagner et al., 1998) with different RNA-binding affinities and specificities for its target mRNAs-such as c-fos, c-myc, TNF $\alpha$, VEGF, and COX-2 (Brewer, 1991; Loflin et al., 1999; Lasa et al., 2000; Xu et al., 2001; Fellows et al., 2012).

In addition to recognizing AU-rich sequences at the $3^{\prime}$ UTR of target mRNAs, some ARE-RBPs are able to activate splice $5^{\prime}$ sites followed by U-rich sequences. This is the case of TIA-1 and TIAR, that upregulate the translation of their own coding mRNAs (Le Guiner et al., 2001). Conversely, although consistent with their functional redundancy, their translation levels are negatively cross-regulated by each other (Le Guiner et al., 2001; Izquierdo and Valcárcel, 2007b; Pullmann et al., 2007) (Table 1, dotted square). Interestingly, TIA-1 and TIAR share common functions, acting as negative translational regulators of diverse mRNAs-such as c-myc, TNF $\alpha$, VEGF, and COX-2-and are able to compensate for each other (Gueydan et al., 1999; Piecyk et al., 2000; Zhang et al., 2002; Cok et al., 2003; Dixon et al., 2003; Lu et al., 2009; Hamdollah Zadeh et al., 2015). In addition, it has been shown that HuR positively controls TIA-1 expression by enhancing its mRNA stability (Pullmann et al., 2007). By contrast,
TIA-1 knockdown causes a marked increase in HuR levels, indicating that TIA-1 may contribute to lowering HuR levels in the cell (Kawai et al., 2006) (Table 1, black square). This is of great importance because both HuR and TIA-1 bind to cytochrome $c$ (Cc) mRNA, respectively promoting or inhibiting its translation without affecting its mRNA stability. The struggle between HuR (antiapoptotic factor) and TIA-1 (proapoptotic factor) for the control of $\mathrm{C} c$ mRNA translation underlies possible mechanisms to regulate both cellular respiration and programmed cell death. A direct binding between HuR and TIAR mRNA has also been reported (Pullmann et al., 2007) but, unexpectedly, TIAR does not seem to complex with $\mathrm{C} c$ mRNA, despite the extensively shared homology between TIAR and TIA-1 (Kawai et al., 2006).

\section{FACTORS THAT MODULATE ARE-RBP/mRNA INTERACTIONS}

Several examples of cross-talk between ARE-RBPs highlight that there must be an intricate network of regulatory events that lead to the prevalence of one RBP over the others when recognizing the same mRNA target. Thus, the regulatory activity of RBPs on gene expression is dynamic and adapts to cell conditions continuously. In this section, we briefly describe those factors for which there is evidence of their influence on the interaction between RBPs and their mRNA targets (Supplemental Figure 1).

\section{RBP Isoforms}

Alternative splicing is a highly regulated process that allows the synthesis of multiple different transcripts from the same gene, and is therefore an important source of protein diversity and complexity. The slight differences in amino acid sequence between isoforms can be determining for their function (GallegoPáez et al., 2017). For example, TIA-1 and TIAR present two isoforms $-a$ and $b$-in humans. Isoform $a$ in TIA- 1 and TIAR possesses 11 or 17 extra amino acids, respectively, that are critical for distinct functional properties. For instance, only TIAR isoform $a$-but not TIAR $b$ and none of TIA- 1 isoforms-has a translational silencing activity on the proteolytic enzyme Human Matrix Metalloproteinase-13 (HMMP13) in HEK293 cells. High levels of expression of HMMP13 have been documented in certain subset of cancers. Therefore, its downregulation by TIAR $a$ may act as a tumor suppression mechanism (Yu et al., 2003).

As previously mentioned, AUF1 isoforms come from the alternative splicing of the same pre-mRNA. They differ as a function of the presence or absence of two independent domains encoded by exons 2 and 7 . While p37 ${ }^{\text {AUF1 }}$ lacks both domains, $\mathrm{p} 42^{\mathrm{AUF} 1}$ and $\mathrm{p} 45^{\mathrm{AUF} 1}$ include a 49 -amino acid domain encoded by exon 7 and $\mathrm{p} 40^{\mathrm{AUF} 1}$ and $\mathrm{p} 45^{\mathrm{AUF} 1}$ both contain a 19 -amino acid domain encoded by exon 2 . Inclusion of the exon 2-encoded sequence reduces the affinity of the first and second binding events of AUF1 dimers toward their mRNA substrates, but incorporation of the exon 7 -encoded sequence increases the affinity of the second binding event. The isoformspecific differences provide unique biochemical characteristics that explain the diversity of AUF1 functions and complex regulation (Zucconi et al., 2010). 
TABLE 1 | Matrix representation of the interaction of selected RBPs (vertical axis) with the mRNA of those RBPs (Upper table) and several ARE-containing mRNA targets (Lower table, horizontal axis).

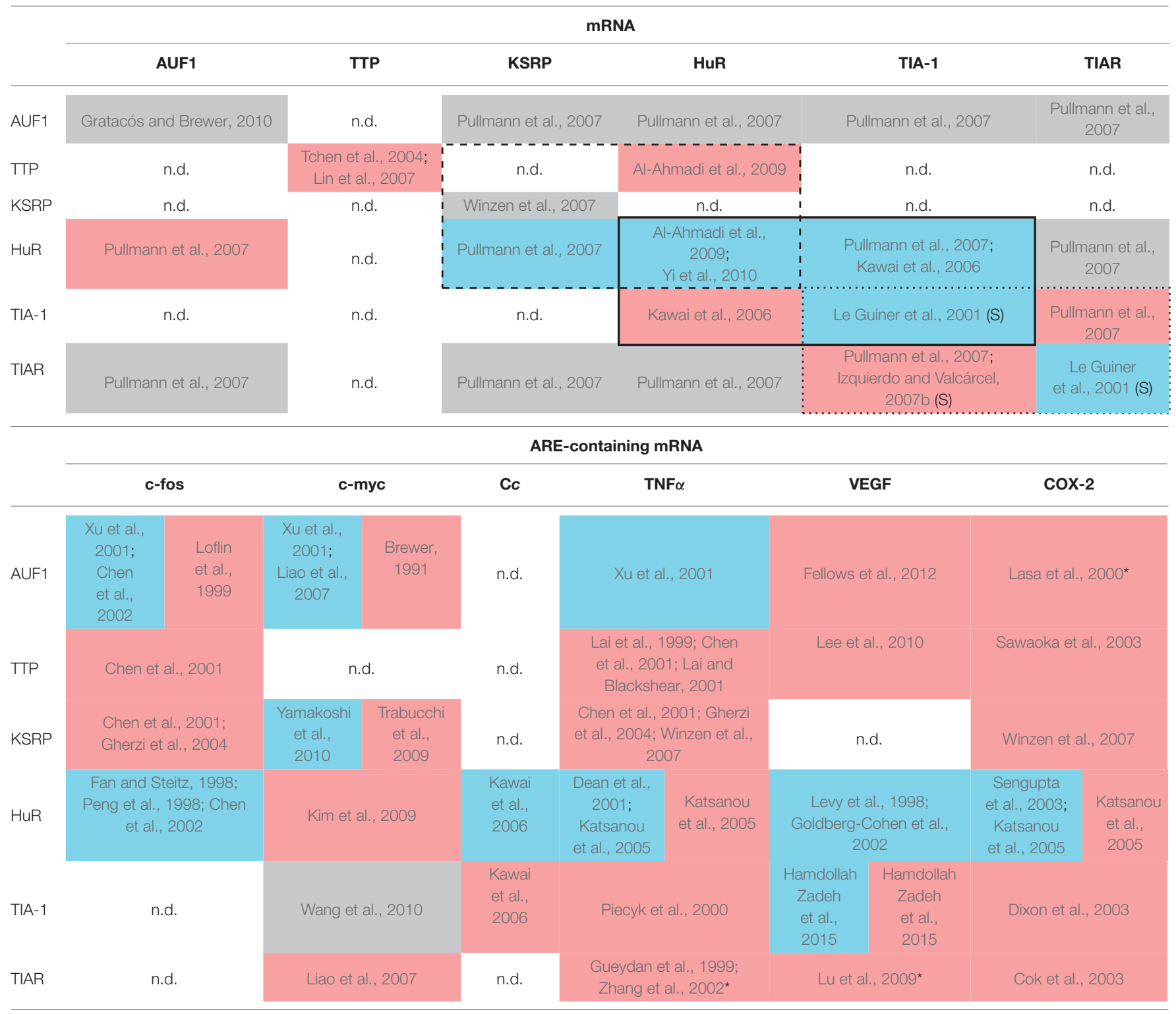

Blue colors show positive regulation, whereas negative regulations are colored in red. Gray color indicates interactions that have been described but the effects were not examined. n.d., non-described; S, Splicing; *, Postulated regulations. The cross-talk between TTP, KSRP and HuR is highlighted by a dashed square; between HuR and TIA-1 by a black square; and between TIA-1 and TIAR by a dotted square.

\section{RBP Post-Translational Modifications}

Post-Translational Modifications (PTMs), such as phosphorylation, isomerization, methylation, NEDDylation, acetylation, and ubiquitination of RBPs have a major influence on their function and/or their affinity toward their targets, with the consequent impact on mRNA stability, turnover and translation efficiency (Lee, 2012). For instance, the phosphorylation of $\mathrm{p} 40^{\mathrm{AUFl}}$ in residues Ser83 and Ser87 influences the sequential binding of dimers to TNF $\alpha$ mRNA (Wilson et al., 2003). Single phosphorylation of Ser83 inhibits by $40 \%$ the initial dimer binding to mRNA substrate, whereas Ser87-single phosphorylation induces a 2 -fold increase in the affinity of the second binding event. In addition, when simultaneous phosphorylation of both residues occurs, the negative effect on the binding affinity of Ser83 prevails over the positive effect of Ser87 (Wilson et al., 2003). Several phosphorylation sites have also been identified in TTP (Cao et al., 2006, 2014). Phosphorylated TTP binds with a lower affinity than the dephosphorylated TTP to target AREs (Carballo et al., 2001; Hitti et al., 2006). Phosphorylation of RBPs can also modify their activity without altering the affinity for mRNA targets. Such is the case of TIA-1 and TIAR, whose splicing control over the Fas gene sequence determines the expression of the pro-apoptotic membrane-bound form in detriment of the anti-apoptotic 
soluble one (Izquierdo and Valcárcel, 2007a). Moreover, HuR methylation has been proposed to increase the nuclear export of $\mathrm{HuR}$, which could be important for mRNA localization (Li et al., 2002). NEDDylation of HuR increases its stability and lifetime, which, in turn, can affect the total levels of HuR target mRNAs due to its main stabilizing action (Embade et al., 2012; Fernández-Ramos and Martínez-Chantar, 2015).

\section{RBP Conformational Changes}

ARE-RBPs can undergo conformational changes upon binding to their targets (Ellis and Jones, 2008). These variations can be detected in the contact surface with mRNAs as well as in distant areas, meaning that ARE-RBPs can adapt both the local and global structure. An example of conformational changes that influence ARE recognition has been reported for KSRP. An interdomain re-arrangement, that orients the two central $\mathrm{KH}$ domains and their RNA-binding surfaces creating a two-domain unit, is crucial for its role in ARE-mediated mRNA decay (Supplemental Figure 2) (Díaz-Moreno et al., 2010). Additionally, some of the PTMs mentioned above can also influence the conformation of RBPs. Hence, the phosphorylation of Ser193 within the Nterminal $\mathrm{KH}$ motif (KH1) of KSRP leads to the unfolding of this structurally atypical and unstable domain, creating a binding site for 14-3-3 $\zeta$, driving the nuclear localization of KSRP and controlling its mRNA-degradation activity (Díaz-Moreno et al., 2009).

Another important regulation factor is the RBP oligomerization state upon mRNA recognition. HuR RRM1 domain and RRM1-2 di-domain (the main platform of cytoplasmic mRNA binding in HuR) form homodimers in solution (Benoit et al., 2010). This phenomenon is dependent on Cys13, which is able to form disulfide bonds. Such homodimerization may modulate $\mathrm{HuR}$ function upon oxidative stress. Moreover, the HuR RRM3 domain has been found to be involved in protein oligomerization and RNA recognition, both functions regulated by the same RRM but using different surfaces at opposite sides of the domain. The conserved Trp261 residue is key for dimerization, as the substitution by glutamic acid alters its dimerization dynamics and stabilizes the monomeric state (Scheiba et al., 2014; Díaz-Quintana et al., 2015).

\section{Cellular Conditions and Stress Response}

Eukaryotic cells have evolved sophisticated strategies to overcome stress. One of them is the assembly of Stress Granules (SGs), which allows mRNA translation silencing and protection from degradation. Among RBPs with critical roles in neurodegenerative diseases, TIA-1 proteins are essential in SG formation (Mazan-Mamczarz et al., 2006; Vanderweyde et al., 2012). Hence, under hypoxic conditions, TIA-1 and TIAR block the expression of hypoxia-inducible factor (HIF)- $1 \alpha$ through binding to its ARE-containing mRNA (Gottschald et al., 2010). Inhibition of this transcription factor is enhanced when both RBPs are organized into SGs. In addition, HuR also aggregates into SGs to halt the translation of specific housekeeping mRNAs under stress conditions (Bergalet et al., 2011). The deregulation of SGs results in cytoplasmic accumulation and subsequent pathologies such as Parkinson and Alzheimer (Vanderweyde et al., 2012).

Variations in $\mathrm{pH}$ values can also modulate the binding of TIA-1 to nucleic acids, acting as a $\mathrm{pH}$-dependent molecular switch. The $\mathrm{p} K_{\mathrm{a}}$ values of the histidine imidazole groups of TIA-1 RRM2 and RRM3 are substantially higher in complexes with short RNA and DNA oligonucleotides than in the isolated domains. Interestingly, those $\mathrm{p} K_{\mathrm{a}}$ values are also controlled by slight environmental pH changes (Cruz-Gallardo et al., 2013, 2015). This fact provides valuable information to understand the $\mathrm{pH}$ effect on ARE-RBPs when shuttling among cellular compartments with different $\mathrm{pHs}$ (nucleus, cytoplasm, SGs, etc.).

During oxidative stress, AUF1 binding to mRNAs containing 8-oxo-7,8-dihydro-guanine could play a role in the selective elimination of oxidized mRNA by presumably driving their degradation (Ishii et al., 2015). Finally, HuR localization can also be altered upon different stress signals such us UV, actinomycin $\mathrm{D}$ or hydrogen peroxide, leading to the cytoplasmic accumulation of the protein. However, after a heat shock treatment, the decrease in HuR protein levels enhances cell survival. This phenomenon is linked to the ubiquitination of Lys182, promoting protein degradation, which finally interferes with the binding of HuR to its target mRNAs (Abdelmohsen et al., 2009).

\section{mRNA Specific Sequence and Conformation}

RBPs do not interact with the same affinity with every ARE-containing mRNA; instead, preferences exist for certain sequences. For instance, TIA-1 RRM domains display different binding constants during nucleic acid recognition. Indeed, the central domains (RRM2 and RRM3) constitute the mRNA binding platform of the protein. RRM2 drives the interaction with RNA, and shows the highest affinities for pyrimidine rich sequences. In turn, RRM3 enhances the overall TIA-1 binding affinity for RNA, preferentially interacting with C-rich motifs (Cruz-Gallardo et al., 2014; Wang et al., 2014; Waris et al., 2017). Moreover, HuR and TIAR interact with $\mathrm{U}$ - and AU-rich mRNAs in vitro, with greater affinity $(\approx 10$-fold) for the former ones. This higher affinity for U-rich mRNAs results from a higher association rate constant, mainly derived from the presence of a greater number of effective binding positions (Kim et al., 2011). However, in vivo analysis showed that HuR stabilized AU-rich mRNAs to a greater extent than U-rich mRNAs (Brennan and Steitz, 2001). Additionally, the KH domains of KSRP behave as independent binding modules with different affinities for AUrich mRNAs, explaining the broad range of targets recognized by the protein. While the fourth $\mathrm{KH}$ domain (KH4) is primarily responsible for mRNA binding and decay through an essential structural element in its $\beta_{4}, \mathrm{KH} 3$ is also necessary to drive the recognition of $\mathrm{AU}$ - and G-rich sequences. On the other hand, all $\mathrm{KH}$ domains show a clear negative selection for C-rich sequences (García-Mayoral et al., 2007, 2008). Interestingly, many RNA targets of $\mathrm{HuR}$, which acts antagonistically to KSRP, often contain isolated Gs but very rarely Cs (López De Silanes et al., 2004). 
Conformational changes in the ARE-mRNA structure have also the potential to regulate the binding affinity of RBPs. These changes may precede the binding of RBPs, as occurs with TNF $\alpha$ mRNA as a consequence of the stabilization of its folding mediated by divalent cations such as $\mathrm{Mg}^{2+}$ (Wilson et al., $2001 \mathrm{a}, \mathrm{b})$. In addition, the AU-rich motif of TNF $\alpha$ mRNA can also adopt a hairpin-like structure that inhibits specifically p37 $7^{\mathrm{AUF} 1}$ binding, but hardly affects its interaction with HuR (Fialcowitz et al., 2005). On the other hand, the association of RBPs can cause local changes in the structure of their cognate mRNAs, which may affect the recruitment of new trans-acting factors or establish preferences for one RBP over another. Consequently, these changes would directly impact on the turnover rates of such ARE-containing mRNAs (Wilson et al., 2001b; Zucconi et al., 2010).

\section{DNA Recognition and Role of RBPs in DNA Damage Response}

Some ARE-RBPs also have the ability to bind to DNA. Importantly, in the case of TIA-1 and TIAR, it occurs with a markedly higher affinity than both RBPs show for their mRNA targets (Suswam et al., 2005; Waris et al., 2017). In fact, it has been hypothesized that the formation of the RBP-mRNA complexes would require the direct displacement of the RBP from its DNAbinding site by the polymerase. This dual binding capacity of TIA- 1 and TIAR could be potentially providing a link between transcription and splicing (Suswam et al., 2005; Mcalinden et al., 2007; Waris et al., 2017).

Interestingly, several RBPs are involved in DNA Damage Response (DDR), being recruited to DNA breaks in a Poly (ADPRibose) (PAR)-dependent manner and/or forming liquid-like compartments by phase separation (Kai, 2016). The formation of these phases requires the presence of an unstructured PrionRelated Domain (PRD) like the one that is present in TIA-1 and TIAR proteins (Gilks et al., 2004). Importantly, abnormal phase separation by mutated $\mathrm{PRD}$-containing proteins leads to pathological protein aggregation and is associated with neurodegenerative and aging-associated diseases (Kai, 2016).

\section{CONCLUSIONS AND FUTURE PERSPECTIVES}

Before being translated into proteins, mRNAs are subjected to a sequential and strict control by RBPs exerted by the

\section{REFERENCES}

Abdelmohsen, K., Srikantan, S., Yang, X., Lal, A., Kim, H. H., Kuwano, Y., et al. (2009). Ubiquitin-mediated proteolysis of HuR by heat shock. EMBO J. 28, 1271-1282. doi: 10.1038/emboj.2009.67

Al-Ahmadi, W., Al-Ghamdi, M., Al-Haj, L., Al-Saif, M., and Khabar, K. S. A. (2009). Alternative polyadenylation variants of the RNA binding protein, HuR: abundance, role of AU-rich elements and auto-Regulation. Nucleic Acids Res. 37, 3612-3624. doi: 10.1093/nar/ gkp223 recognition of AREs in their $3^{\prime}$-UTRs. Regulation of mRNA homeostasis through ARE-RBPs allows the fine tuning of responses by controlling mRNA translation, degradation, or storage in diverse eukaryotic cell compartments (Glisovic et al., 2008; Ganguly et al., 2016). As reviewed above, many examples of ARE-RBP interactions have been reported in the literature, but it is still not well-understood how RBP domains collaborate or compete with each other for the modulation of its targets. The proper inspection of such a convoluted interplay between RBPs requires the combination of different methods in order to compensate the specific strengths and weaknesses of each technique. On the other hand, it becomes more and more evident the need of a transition from a static to a dynamic point of view to take into account the biological environment during RNA binding. Consequently, the integration of the information obtained by in vivo approaches with the structural data would be of great interest. Moreover, the understanding of the ARE-mRNAs processing in highly dynamic and often transient macromolecular complexes also remains challenging (Rissland, 2017). Finally, the key role of intrinsically disordered connecting linkers between RNA binding domains has acquired significant relevance in the latest reports (Basu and Bahadur, 2016). Altogether, the examples of mRNAprotein interactions by ARE-RBPs herein reviewed highlight the need for integrative studies to fully understand such a fine tuned regulation.

\section{AUTHOR CONTRIBUTIONS}

All authors listed have made a substantial, direct, and intellectual contribution to the work, and approved it for publication.

\section{ACKNOWLEDGMENTS}

Financial support was provided by the Andalusian Government (P11-CVI-7216, BIO198); the Spanish Ministry of Economy, Industry and Competitiveness (BFU2015-71017-P); the Spanish Ministry of Education, Culture and Sports (FPU013/04373, FPU016/01513) and the Ramón Areces Foundation.

\section{SUPPLEMENTARY MATERIAL}

The Supplementary Material for this article can be found online at: https://www.frontiersin.org/articles/10.3389/fmolb. 2017.00071/full\#supplementary-material 
Bergalet, J., Fawal, M., López, C., Desjobert, C., Lamant, L., Delsol, G., et al. (2011). HuR-mediated control of C/EBPbeta mRNA stability and translation in ALK-positive anaplastic large cell lymphomas. Mol. Cancer Res. 9, 485-496. doi: 10.1158/1541-7786.MCR-10-0351

Brennan, C. M., and Steitz, J. A. (2001). HuR and mRNA stability. Cell. Mol. Life Sci. 58, 266-277. doi: 10.1007/PL00000854

Brewer, G. (1991). An A + U-rich element RNA-binding factor regulates c-myc mRNA stability in vitro. Mol. Cell. Biol. 11, 2460-2466. doi: 10.1128/MCB.11.5.2460

Cao, H., Deterding, L. J., Venable, J. D., Kennington, E. A., Yates, J. R., Tomer, K. B., et al. (2006). Identification of the anti-inflammatory protein tristetraprolin as a hyperphosphorylated protein by mass spectrometry and site-directed mutagenesis. Biochem. J. 394, 285-297. doi: 10.1042/BJ20051316

Cao, H., Deterding, L. J., and Blackshear, P. J. (2014). Identification of a major phosphopeptide in human Tristetraprolin by phosphopeptide mapping and mass spectrometry. PLOS ONE 9:e100977. doi: 10.1371/journal.pone. 0100977

Carballo, E., Cao, H., Lai, W. S., Kennington, E. A., Campbell, D., and Blackshear, P. J. (2001). Decreased sensitivity of Tristetraprolin-deficient cells to p38 inhibitors suggests the involvement of Tristetraprolin in the p38 signaling pathway. J. Biol. Chem. 276, 42580-42587. doi: 10.1074/jbc.M104953200

Chen, C. Y., Gherzi, R., Ong, S. E., Chan, E. L., Raijmakers, R., Pruijn, G. J., et al. (2001). AU binding proteins recruit the exosome to degrade ARE-containing mRNAs. Cell 107, 451-464. doi: 10.1016/S0092-8674(01)00578-5

Chen, C. Y., Xu, N., and Shyu, A. B. (2002). Highly selective actions of HuR in antagonizing AU-rich element-mediated mRNA destabilization. Mol. Cell. Biol. 22, 7268-7278. doi: 10.1128/MCB.22.20.7268-7278.2002

Clery, A., Blatter, M., and Allain, F. H. (2008). RNA recognition motifs: boring? Not quite. Curr. Opin. Struct. Biol. 18, 290-298. doi: 10.1016/j.sbi.2008.04.002

Cok, S. J., Acton, S. J., and Morrison, A. R. (2003). The proximal region of the $3^{\prime}$-untranslated region of cyclooxygenase- 2 is recognized by a multimeric protein complex containing HuR, TIA-1, TIAR, and the heterogeneous nuclear ribonucleoprotein U. J. Biol. Chem. 278, 36157-36162. doi: 10.1074/jbc.M302547200

Cruz-Gallardo, I., Aroca, A., Gunzburg, M. J., Sivakumaran, A., Yoon, J. H., Angulo, J., et al. (2014). The binding of TIA-1 to RNA C-rich sequences is driven by its C-terminal RRM domain. RNA Biol. 11, 766-776. doi: $10.4161 /$ rna.28801

Cruz-Gallardo, I., Aroca, A., Persson, C., Karlsson, B. G., and Díaz-Moreno, I. (2013). RNA binding of T-cell intracellular antigen-1 (TIA-1) C-terminal RNA recognition motif is modified by $\mathrm{pH}$ conditions. J. Biol. Chem. 288, 25986-25994. doi: 10.1074/jbc.M113.489070

Cruz-Gallardo, I., Del Conte, R., Velázquez-Campoy, A., García-Maurino, S. M., and Díaz-Moreno, I. (2015). A non-invasive NMR method based on histidine imidazoles to analyze the $\mathrm{pH}$-modulation of protein-nucleic acid interfaces. Chem. Eur. J. 21, 7588-7595. doi: 10.1002/chem.201405538

Daubner, G. M., Clery, A., and Allain, F. H. (2013). RRM-RNA recognition: NMR or crystallography and new findings. Curr. Opin. Struct. Biol. 23, 100-108. doi: 10.1016/j.sbi.2012.11.006

Dean, J. L. E., Wait, R., Mahtani, K. R., Sully, G., Clark, A. R., and Saklatvala, J. (2001). The $3^{\prime}$ untranslated region of tumor necrosis factor alpha mRNA Is a target of the mRNA-stabilizing factor HuR. Mol. Cell. Biol. 21, 721-730. doi: 10.1128/MCB.21.3.721-730.2001

Díaz-Moreno, I., Hollingworth, D., Frenkiel, T. A., Kelly, G., Martin, S., Howell, S., et al. (2009). Phosphorylation-mediated unfolding of a $\mathrm{KH}$ domain regulates KSRP localization via 14-3-3 binding. Nat. Struct. Mol. Biol. 16, 238-246. doi: $10.1038 / \mathrm{nsmb} .1558$

Díaz-Moreno, I., Hollingworth, D., Kelly, G., Martin, S., García-Mayoral, M., Briata, P., et al. (2010). Orientation of the central domains of KSRP and its implications for the interaction with the RNA targets. Nucleic Acids Res. 38, 5193-5205. doi: 10.1093/nar/gkq216

Díaz-Quintana, A., García-Maurino, S. M., and Díaz-Moreno, I. (2015). Dimerization model of the C-terminal RNA recognition motif of HuR. FEBS Lett. 589, 1059-1066. doi: 10.1016/j.febslet.2015.03.013

Dixon, D. A., Balch, G. C., Kedersha, N., Anderson, P., Zimmerman, G. A., Beauchamp, R. D., et al. (2003). Regulation of Cyclooxygenase-2 expression by the translational silencer TIA-1. J. Exp. Med. 198, 475-481. doi: $10.1084 /$ jem. 20030616
Ellis, J. J., and Jones, S. (2008). Evaluating conformational changes in protein structures binding RNA. Proteins 70, 1518-1526. doi: 10.1002/prot.21647

Embade, N., Fernández-Ramos, D., Varela-Rey, M., Beraza, N., Sini, M., Gutierrez De Juan, V., et al. (2012). Murine double minute 2 regulates $\mathrm{Hu}$ antigen $\mathrm{R}$ stability in human liver and colon cancer through NEDDylation. Hepatology.55, 1237-1248. doi: 10.1002/hep.24795

Fan, X. C., and Steitz, J. A. (1998). Overexpression of HuR, a nuclear-cytoplasmic shuttling protein, increases the in vivo stability of ARE-containing mRNAs. EMBO J. 17, 3448-3460. doi: 10.1093/emboj/17.12.3448

Fellows, A., Griffin, M. E., Petrella, B. L., Zhong, L., Parvin-Nejad, F. P., Fava, R., et al. (2012). AUF1/hnRNP D represses expression of VEGF in macrophages. Mol. Biol. Cell. 23, 1414-1422. doi: 10.1091/mbc.E11-06-0545

Fernández-Ramos, D., and Martínez-Chantar, M. L. (2015). NEDDylation in liver cancer: the regulation of the RNA binding protein $\mathrm{Hu}$ antigen R. Pancreatology 15, S49-S54. doi: 10.1016/j.pan.2015.03.006

Fialcowitz, E. J., Brewer, B. Y., Keenan, B. P., and Wilson, G. M. (2005). A hairpin-like structure within an AU-rich mRNA-destabilizing element regulates trans-factor binding selectivity and mRNA decay kinetics. J. Biol. Chem. 280, 22406-22417. doi: 10.1074/jbc.M500618200

Gallego-Páez, L. M., Bordone, M. C., Leote, A. C., Saraiva-Agostinho, N., Ascensao-Ferreira, M., and Barbosa-Morais, N. L. (2017). Alternative splicing: the pledge, the turn, and the prestige: the key role of alternative splicing in human biological systems. Hum. Genet. 136, 1015-1042. doi: 10.1007/s00439-017-1790-y

Gama-Carvalho, M., and Carmo-Fonseca, M. (2001). The rules and roles of nucleocytoplasmic shuttling proteins. FEBS Lett. 498, 157-163. doi: 10.1016/S0014-5793(01)02487-5

Ganguly, K., Giddaluru, J., August, A., and Khan, N. (2016). Post-transcriptional regulation of immunological responses through riboclustering. Front. Immunol. 7:161. doi: 10.3389/fimmu.2016.00161

García-Mayoral, M. F., Díaz-Moreno, I., Hollingworth, D., and Ramos, A. (2008). The sequence selectivity of KSRP explains its flexibility in the recognition of the RNA targets. Nucleic Acids Res. 36, 5290-5296. doi: 10.1093/nar/gkn509

García-Mayoral, M. F., Hollingworth, D., Masino, L., Díaz-Moreno, I., Kelly, G., Gherzi, R., et al. (2007). The structure of the C-terminal KH domains of KSRP reveals a noncanonical motif important for mRNA degradation. Structure 15, 485-498. doi: 10.1016/j.str.2007.03.006

Gherzi, R., Lee, K. Y., Briata, P., Wegmuller, D., Moroni, C., Karin, M., et al. (2004). A KH domain RNA binding protein, KSRP, promotes ARE-directed mRNA turnover by recruiting the degradation machinery. Mol. Cell. 14, 571-583. doi: 10.1016/j.molcel.2004.05.002

Gilks, N., Kedersha, N., Ayodele, M., Shen, L., Stoecklin, G., Dember, L. M., et al. (2004). Stress granule assembly is mediated by prion-like aggregation of TIA-1. ?Mol. Biol. Cell. 15, 5383-5398. doi: 10.1091/mbc.E04-08-0715

Glisovic, T., Bachorik, J. L., Yong, J., and Dreyfuss, G. (2008). RNA-binding proteins and post-transcriptional gene regulation. FEBS Lett. 582, 1977-1986. doi: 10.1016/j.febslet.2008.03.004

Goldberg-Cohen, I., Furneauxb, H., and Levy, A. P. (2002). A 40-bp RNA element that mediates stabilization of vascular endothelial growth factor mRNA by HuR. J. Biol. Chem. 277, 13635-13640. doi: 10.1074/jbc.M108703200

Gottschald, O. R., Malec, V., Krasteva, G., Hasan, D., Kamlah, F., Herold, S., et al. (2010). TIAR and TIA-1 mRNA-binding proteins co-aggregate under conditions of rapid oxygen decline and extreme hypoxia and suppress the HIF-1 $\alpha$ pathway. J. Mol. Cell. Biol. 2, 345-356. doi: 10.1093/jmcb/mjq032

Gratacós, F. M., and Brewer, G. (2010). The role of AUF1 in regulated mRNA decay. RNA 1, 457-473. doi: 10.1002/wrna.26

Gueydan, C., Droogmans, L., Chalon, P., Huez, G., Caput, D., and Kruys, V. (1999). Identification of TIAR as a protein binding to the translational regulatory AU-rich element of tumor necrosis factor alpha mRNA. J. Biol. Chem. 274, 2322-2326. doi: 10.1074/jbc.274.4.2322

Hamdollah Zadeh, M. A., Amin, E. M., Hoareau-Aveilla, C., Domingo, E., Symonds, K. E., Ye, X., et al. (2015). Alternative splicing of TIA-1 in human colon cancer regulates VEGF isoform expression, angiogenesis, tumour growth and bevacizumab resistance. Mol. Oncol. 9, 167-178. doi: 10.1016/j.molonc.2014.07.017

Hitti, E., Iakovleva, T., Brook, M., Deppenmeier, S., Gruber, A. D., Radzioch, D., et al. (2006). Mitogen-activated protein kinase-activated protein kinase 2 regulates tumor necrosis factor mRNA stability and 
translation mainly by altering Tristetraprolin expression, stability, and binding to adenine/uridine-rich element. Mol. Cell. Biol. 26, 2399-2407. doi: 10.1128/MCB.26.6.2399-2407.2006

Ishii, T., Hayakawa, H., Sekiguchi, T., Adachi, N., and Sekiguchi, M. (2015). Role of AUF1 in elimination of oxidatively damaged messenger RNA in human cells. Free Radic. Biol. Med. 79, 109-116. doi: 10.1016/j.freeradbiomed.2014.11.018

Izquierdo, J. M., and Valcárcel, J. (2007a). Fas-activated serine/threonine kinase (FAST K) synergizes with TIA-1/TIAR proteins to regulate Fas alternative splicing. J. Biol. Chem. 282, 1539-1543. doi: 10.1074/jbc.C600198200

Izquierdo, J. M., and Valcárcel, J. (2007b). Two isoforms of the T-cell intracellular antigen 1 (TIA-1) splicing factor display distinct splicing regulation activities. Control of TIA-1 isoform ratio by TIA-1-related protein. J. Biol. Chem. 282, 19410-19417. doi: 10.1074/jbc.M700688200

Kai, M. (2016). Roles of RNA-binding proteins in DNA damage response. Int. J. Mol. Sci. 17:310. doi: 10.3390/ijms17030310

Katsanou, V., Papadaki, O., Milatos, S., Blackshear, P. J., Anderson, P., Kollias, G., et al. (2005). HuR as a negative posttranscriptional modulator in inflammation. ?Mol. Cell. 19, 777-789. doi: 10.1016/j.molcel.2005.08.007

Kawai, T., Lal, A., Yang, X., Galban, S., Mazan-Mamczarz, K., and Gorospe, M. (2006). Translational control of cytochrome $c$ by RNAbinding proteins TIA-1 and HuR. Mol. Cell. Biol. 26, 3295-3307. doi: 10.1128/MCB.26.8.3295-3307.2006

Khabar, K. S. (2005). The AU-rich transcriptome: more than interferons and cytokines, and its role in disease. J. Interferon Cytokine Res. 25, 1-10. doi: $10.1089 /$ jir.2005.25.1

Kim, H. H., Kuwano, Y., Srikantan, S., Lee, E. K., Martindale, J. L., and Gorospe, M. (2009). HuR recruits let-7/RISC to repress c-Myc expression. Genes Dev. 23, 1743-1748. doi: 10.1101/gad.1812509

Kim, H. S., Wilce, M. C. J., Yoga, Y. M. K., Pendini, N. R., Gunzburg, M. J., Cowieson, N. P., et al. (2011). Different modes of interaction by TIAR and HuR with target RNA and DNA. Nucleic Acids Res. 39, 1117-1130. doi: 10.1093/nar/gkq837

Lai, W. S., and Blackshear, P. J. (2001). Interactions of CCCH zinc finger proteins with mRNA: Tristetraprolin-mediated AU-rich element-dependent mRNA degradation can occur in the absence of a poly(A) tail. J. Biol. Chem. 276, 23144-23154. doi: 10.1074/jbc.M100680200

Lai, W. S., Carballo, E., Strum, J. R., Kennington, E. A., Phillips, R. S., and Blackshear, P. J. (1999). Evidence that Tristetraprolin binds to AU-Rich elements and promotes the deadenylation and destabilization of tumor necrosis factor alpha mRNA. Mol. Cell Biol. 19, 4311-4323. doi: 10.1128/MCB.19.6.4311

Lasa, M., Mahtani, K. R., Finch, A., Brewer, G., Saklatvala, J., and Clark, A. R. (2000). Regulation of cyclooxygenase 2 mRNA stability by the mitogenactivated protein kinase p38 signaling cascade. Mol. Cell. Biol. 20, 4265-4274. doi: 10.1128/MCB.20.12.4265-4274.2000

Lee, E. K. (2012). Post-translational modifications of RNA-binding proteins and their roles in RNA granules. Curr. Protein Pept. Sci. 13, 331-336. doi: $10.2174 / 138920312801619411$

Lee, H. H., Son, Y. J., Lee, W. H., Park, Y. W., Chae, S. W., Cho, W. J., et al. (2010). Tristetraprolin regulates expression of VEGF and tumorigenesis in human colon cancer. Int. J. Cancer. 126, 1817-1827. doi: 10.1002/ijc.24847

Le Guiner, C., Lejeune, F., Galiana, D., Kister, L., Breathnach, R., Stévenin, J., et al. (2001). TIA-1 and TIAR activate splicing of alternative exons with weak $5^{\prime}$ splice sites followed by a U-rich stretch on their own pre-mRNAs. J. Biol. Chem. 276, 40638-40646. doi: 10.1074/jbc.M105642200

Levy, N. S., Chung, S., Furneaux, H., and Levy, A. P. (1998). Hypoxic stabilization of vascular endothelial growth factor mRNA by the RNA-binding protein HuR. J. Biol. Chem. 273, 6417-6423. doi: 10.1074/jbc.273.11.6417

Li, H., Park, S., Kilburn, B., Jelinek, M. A., Henschen-Edman, A., Aswad, D. W., et al. (2002). Lipopolysaccharide-induced methylation of $\mathrm{HuR}$, an mRNA-stabilizing protein, by CARM1. Coactivatorassociated arginine methyltransferase. J. Biol. Chem. 277, 44623-44630. doi: 10.1074/jbc.M206187200

Liao, B., Hu, Y., and Brewer, G. (2007). Competitive binding of AUF1 and TIAR to MYC mRNA controls its translation. Nat. Struct. Mol. Biol. 14, 511-518. doi: $10.1038 /$ nsmb 1249

Lin, N. Y., Lin, C. T., Chen, Y. L., and Chang, C. J. (2007). Regulation of tristetraprolin during differentiation of 3T3-L1 preadipocytes. FEBS J. 274, 867-878. doi: $10.1111 / j .1742-4658.2007 .05632 . x$
Loflin, P., Chen, C.-Y. A., and Shyu, A.-B. (1999). Unraveling a cytoplasmic role for hnRNP D in the in vivo mRNA destabilization directed by the AU-rich element. Genes Dev. 13, 1884-1897. doi: 10.1101/gad.13.14.1884

López De Silanes, I., Zhan, M., Lal, A., Yang, X., and Gorospe, M. (2004). Identification of a target RNA motif for RNA-binding protein HuR. Proc. Natl. Acad. Sci. U.S.A. 101, 2987-2992. doi: 10.1073/pnas.0306 453101

Lu, L., Wang, S., Zheng, L., Li, X., Suswam, E. A., Zhang, X., et al. (2009). Amyotrophic lateral sclerosis-linked mutant SOD1 sequesters $\mathrm{Hu}$ antigen $\mathrm{R}$ (HuR) and TIA-1-related protein (TIAR): implications for impaired posttranscriptional regulation of vascular endothelial growth factor. J. Biol. Chem. 284, 33989-33998. doi: 10.1074/jbc.M109.067918

Matoulkova, E., Michalova, E., Vojtesek, B., and Hrstka, R. (2012). The role of the $3^{\prime}$ untranslated region in post-transcriptional regulation of protein expression in mammalian cells. RNA Biol. 9, 563-576. doi: 10.4161/rna. 20231

Mazan-Mamczarz, K., Lal, A., Martindale, J. L., Kawai, T., and Gorospe, M. (2006). Translational repression by RNA-binding protein TIAR. Mol. Cell. Biol. 26, 2716-2727. doi: 10.1128/MCB.26.7.2716-2727.2006

Mcalinden, A., Liang, L., Mukudai, Y., Imamura, T., and Sandell, L. J. (2007). Nuclear protein TIA-1 regulates COL2A1 alternative splicing and interacts with precursor mRNA and genomic DNA. J. Biol. Chem. 282, 24444-24454. doi: $10.1074 /$ jbc.M702717200

Peng, S. S., Chen, C. Y., Xu, N., and Shyu, A. B. (1998). RNA stabilization by the AU-rich element binding protein, HuR, an ELAV protein. EMBO J. 17, 3461-3470. doi: 10.1093/emboj/17.12.3461

Piecyk, M., Wax, S., Beck, A. R. P., Kedersha, N., Gupta, M., Maritim, B., et al. (2000). TIA-1 is a translational silencer that selectively regulates the expression of TNF- $\alpha . E M B O ~ J .19,4154-4163$. doi: 10.1093/emboj/19.15.4154

Pullmann, R., Kim, H. H., Abdelmohsen, K., Lal, A., Martindale, J. L., Yang, X., et al. (2007). Analysis of turnover and translation regulatory RNA-binding protein expression through binding to cognate mRNAs. Mol. Cell. Biol. 27, 6265-6278. doi: 10.1128/MCB.00500-07

Rissland, O. S. (2017). The organization and regulation of mRNA-protein complexes. Wiley Interdiscip. Rev. RNA 2017, 8. doi: 10.1002/wrna.1369

Sanduja, S., Blanco, F. F., and Dixon, D. A. (2011). The roles of TTP and BRF proteins in regulated mRNA decay. Wiley Interdiscip. Rev. RNA. 2, 42-57. doi: 10.1002/wrna.28

Sawaoka, H., Dixon, D. A., Oates, J. A., and Boutaud, O. (2003). Tristetraprolin binds to the $3^{\prime}$-Untranslated Region of cyclooxygenase-2 mRNA: a polyadenylation variant in a cancer cell line lacks the binding site. J. Biol. Chem. 278, 13928-13935. doi: 10.1074/jbc.M300016200

Scheiba, R. M., De Opakua, A. I., Díaz-Quintana, A., Cruz-Gallardo, I., Martínez-Cruz, L. A., Martínez-Chantar, M. L., et al. (2014). The C-terminal RNA binding motif of HuR is a multi-functional domain leading to HuR oligomerization and binding to U-rich RNA targets. RNA Biol. 11, 1250-1261. doi: $10.1080 / 15476286.2014 .996069$

Sengupta, S., Jang, B. C., Wu, M. T., Paik, J. H., Furneaux, H., and Hla, T. (2003). The RNA-binding protein HuR regulates the expression of cyclooxygenase-2. J. Biol. Chem. 278, 25227-25233. doi: 10.1074/jbc.M301813200

Shen, Z.-J., and Malter, J. S. (2015). Regulation of AU-rich element RNA binding proteins by phosphorylation and the prolyl isomerase Pin1. Biomolecules 5, 412-434. doi: 10.3390/biom5020412

Stoecklin, G., and Anderson, P. (2006). Posttranscriptional mechanisms regulating the inflammatory response. Adv. Immunol. 89, 1-37. doi: 10.1016/S0065-2776(05)89001-7

Suswam, E. A., Li, Y. Y., Mahtani, H., and King, P. H. (2005). Novel DNA-binding properties of the RNA-binding protein TIAR. Nucleic Acids Res. 33, 4507-4518. doi: 10.1093/nar/gki763

Szostak, E., and Gebauer, F. (2013). Translational control by $3^{\prime}$-UTR-binding proteins. Brief. Funct. Genomics. 12, 58-65. doi: 10.1093/bfgp/els056

Tchen, C. R., Brook, M., Saklatvala, J., and Clark, A. R. (2004). The stability of Tristetraprolin mRNA is regulated by mitogen-activated protein kinase p38 and by Tristetraprolin itself. J. Biol. Chem. 279, 32393-32400. doi: 10.1074/jbc.M402059200

Trabucchi, M., Briata, P., García-Mayoral, M., Haase, A. D., Filipowicz, W., Ramos, A., et al. (2009). The RNA-binding protein KSRP promotes the biogenesis of a subset of microRNAs. Nature 459, 1010-1014. doi: 10.1038/nature08025 
Valverde, R., Edwards, L., and Regan, L. (2008). Structure and function of KH domains. FEBS J. 275, 2712-2726. doi: 10.1111/j.1742-4658.2008.06411.x

Vanderweyde, T., Yu, H., Varnum, M., Liu-Yesucevitz, L., Citro, A., Ikezu, T., et al. (2012). Contrasting pathology of the stress granule proteins TIA-1 and G3BP in tauopathies. J. Neurosci. 32, 8270-8283. doi: 10.1523/JNEUROSCI.1592-12.2012

Vogel, C., and Marcotte, E. M. (2012). Insights into the regulation of protein abundance from proteomic and transcriptomic analyses. Nat. Rev. Genet. 13, 227-232. doi: 10.1038/nrg3185

Wagner, B. J., Demaria, C. T., Sun, Y., Wilson, G. M., and Brewer, G. (1998). Structure and genomic organization of the Human AUF1 Gene: alternative pre-mRNA splicing generates four protein isoforms. Genomics 48, 195-202. doi: 10.1006/geno.1997.5142

Wang, I., Hennig, J., Jagtap, P. K., Sonntag, M., Valcárcel, J., and Sattler, M. (2014). Structure, dynamics and RNA binding of the multi-domain splicing factor TIA-1. Nucleic Acids Res. 42, 5949-5966. doi: 10.1093/nar/gku193

Wang, Z., Kayikci, M., Briese, M., Zarnack, K., Luscombe, N. M., Rot, G., et al. (2010). iCLIP predicts the dual splicing effects of TIA-RNA interactions. PLoS Biol. 8:e1000530. doi: 10.1371/journal.pbio.1000530

Waris, S., García-Maurino, S. M., Sivakumaran, A., Beckham, S. A., Loughlin, F. E., Gorospe, M., et al. (2017). TIA-1 RRM23 binding and recognition of target oligonucleotides. Nucleic Acids Res. 45, 4944-4957. doi: 10.1093/nar/gkx102

Wilson, G. M., Lu, J., Sutphen, K., Suarez, Y., Sinha, S., Brewer, B., et al. (2003). Phosphorylation of p40AUF1 regulates binding to A + U-rich mRNAdestabilizing elements and protein-induced changes in ribonucleoprotein structure. J. Biol. Chem. 278, 33039-33048. doi: 10.1074/jbc.M305775200

Wilson, G. M., Sutphen, K., Chuang, K., and Brewer, G. (2001a). Folding of A+Urich RNA elements modulates AUF1 binding. Potential roles in regulation of mRNA turnover. J. Biol. Chem. 276, 8695-8704. doi: 10.1074/jbc.M009848200

Wilson, G. M., Sutphen, K., Moutafis, M., Sinha, S., and Brewer, G. (2001b). Structural remodeling of an A + U-rich RNA element by cation or AUF1 binding. J. Biol. Chem. 276, 38400-38409. doi: 10.1074/jbc.M106509200

Winzen, R., Thakur, B. K., Dittrich-Breiholz, O., Shah, M., Redich, N., Dhamija, S., et al. (2007). Functional analysis of KSRP interaction with the AU-Rich element of Interleukin-8 and identification of inflammatory mRNA targets. Mol. Cell. Biol. 27, 8388-8400. doi: 10.1128/MCB.01493-07
Xu, N., Chen, C.-Y. A., and Shyu, A.-B. (2001). Versatile role for hnRNP D isoforms in the differential regulation of cytoplasmic mRNA turnover. Mol. Cell. Biol. 21, 6960-6971. doi: 10.1128/MCB.21.20.6960-6971.2001

Yamakoshi, H., Kanoh, N., Kudo, C., Sato, A., Ueda, K., Muroi, M., et al. (2010). KSRP/FUBP2 is a binding protein of GO-Y086, a cytotoxic curcumin analogue. ACS Med. Chem. Lett. 1, 273-276. doi: 10.1021/ml1000454

Yi, J., Chang, N., Liu, X., Guo, G., Xue, L., Tong, T., et al. (2010). Reduced nuclear export of HuR mRNA by HuR is linked to the loss of HuR in replicative senescence. Nucleic Acids Res. 38, 1547-1558. doi: 10.1093/nar/ gkp1114

Yu, Q., Cok, S. J., Zeng, C., and Morrison, A. R. (2003). Translational repression of human matrix metalloproteinases-13 by an alternatively spliced form of Tcell-restricted intracellular antigen-related protein (TIAR). J. Biol. Chem. 278, 1579-1584. doi: 10.1074/jbc.M203526200

Zhang, T., Kruys, V., Huez, G., and Gueydan, C. (2002). AU-rich elementmediated translational control: complexity and multiple activities of transactivating factors. Biochem. Soc. Trans. 30, 952-958. doi: 10.1042/bst0300952

Zucconi, B. E., Ballin, J. D., Brewer, B. Y., Ross, C. R., Huang, J., Toth, E. A., et al. (2010). Alternatively expressed domains of AU-rich element RNAbinding protein 1 (AUF1) regulate RNA-binding affinity, RNA-induced protein oligomerization, and the local conformation of bound RNA ligands. J. Biol. Chem. 285, 39127-39139. doi: 10.1074/jbc.M110.180182

Conflict of Interest Statement: The authors declare that the research was conducted in the absence of any commercial or financial relationships that could be construed as a potential conflict of interest.

The reviewer SM-L and handling Editor declared their shared affiliation.

Copyright (C) 2017 García-Mauriño, Rivero-Rodríguez, Velázquez-Cruz, HernándezVellisca, Díaz-Quintana, De la Rosa and Díaz-Moreno. This is an open-access article distributed under the terms of the Creative Commons Attribution License (CC BY). The use, distribution or reproduction in other forums is permitted, provided the original author(s) or licensor are credited and that the original publication in this journal is cited, in accordance with accepted academic practice. No use, distribution or reproduction is permitted which does not comply with these terms. 